\title{
Modelling, analysis and verification of a resonant LLC converter as a power supply for the electromagnetic driving mechanism of an electromagnetic contactor
}

\author{
Borislav Dimitrov, Andrew Cruden \\ Engineering School \\ Southampton University \\ Southampton, UK \\ B.H.Dimitrov@soton.ac.uk, \\ bdimitrov@processmodeling.org, A.J.Cruden@soton.ac.uk
}

\author{
Angel Marinov \\ Department of Electronics and Microelectronics \\ Technical University of Varna \\ Varna, Bulgaria \\ a.marinov@tu-varna.bg
}

\begin{abstract}
The paper presents model based analysis and experimental verification of a half-bridge resonant LLC converter for suppling power to the electromagnetic driving mechanism of an electromagnetic contactor. In the proposed application the convertor - powered either by AC or DC voltage supplies the coil of the contactor with DC voltage. Analytical and experimental results presented, show several important advantages of the proposed topology: versatility in terms of input voltages - both $\mathrm{AC}$ and $\mathrm{DC}$ are accepted; stability over wide voltage range; omission of overvoltages - common to electromagnetic systems; reduced power consumption.
\end{abstract}

Keywords-electromagnetic contactor, half bridge resonant LLC converter, power supply

\section{INTRODUCTION}

The driving systems of modern high power electromagnetic contactors are usually powered by electronic converters [1]. This is especially true when considering devices that commutate currents above 100A. The application of electronic converters improves upon various properties of the overall system, where some of the major advantages include [2]: (1) stability over a wide range of input voltages; (2) omission of overvoltages generated by the electromagnetic system; (3) reduced dependence on other loads in the relay system. The block diagram of an electromagnetic contactor and its driving converter is shown on figure 1.

Considering the converter - various circuit solutions exists, where the most frequently transformerless topologies such as buck or buck-boost are used. When controlled by specialized integrated circuits (ASIC) or microcontrollers those converter solutions allow for different benefits including lower total harmonic distortions (THD) and power factor correction (PFC).

Despite the widespread use of those solutions some specifics considering their operation and modes, as well as the implementation of different topologies are not well presented in literature. This is especially true when specialized topologies such as LLC resonant converters are used, where several interesting points exists such as: zero voltage switching (ZVS) to improve efficiency; transient turn-on and turn-off processes; improved reliability [3, 4] - due to the better switching characteristics. dependency between electrical and mechanical characteristics; etc. Furthermore there are few discussions on the design of the contactor's electromagnetic system where in some cases the AC electromagnet has to be powered by DC Voltage [5].

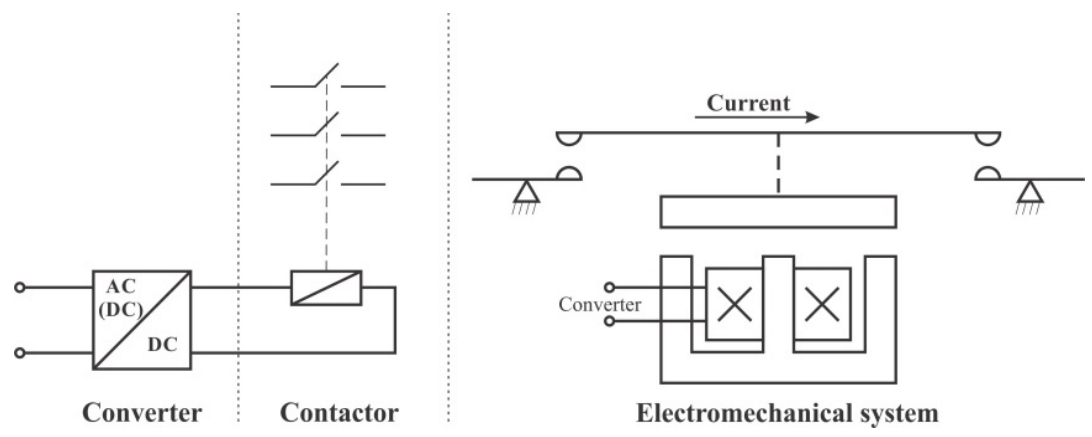

Fig. 1. Block diagram of a system electronic converter - electromagnetic contactor 


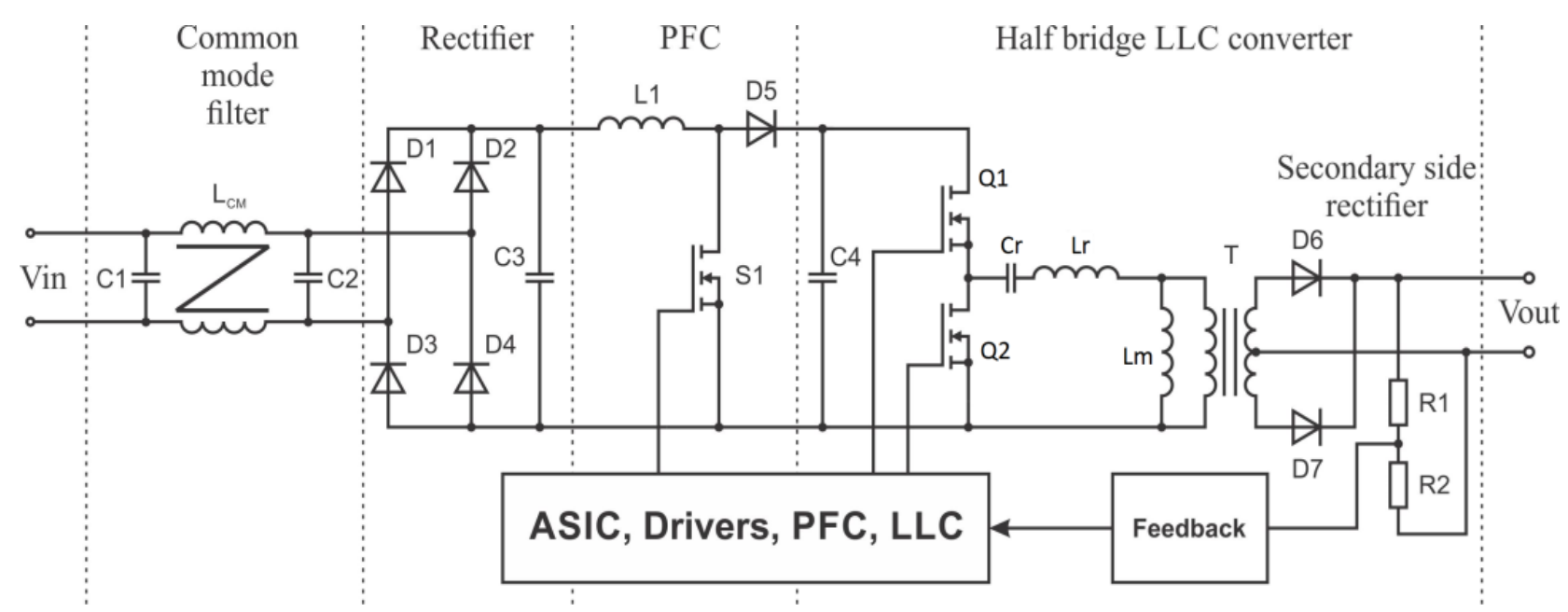

Fig. 2. Suggested LLC topology

The use of an LLC converter can improve the contactor system by: adding more flexibility (DC and AC voltage allowed); providing superior efficiency (ZVS) compared to conventional converters; reducing overvoltages and overcurrents. Taking this into consideration the current paper focuses on modeling and verifying the application and advantages of an off-line LCC resonant convertor as a supply for driving the electromechanical system of a contactor.

\section{SUGGESTED CONCEPT, DESIGN AND MODELLING}

\section{A. Suggested concpet}

The studied topology is presented at figure 2. Its main structure includes four main blocks: (1) Common mode filter and full bridge rectifier; (2) Boost converter with PFC; (3) Half-bridge LLC converter; (4) Second side rectification and feedback.

\section{B. System modelling}

The most important part of the suggested power supply system is the LLC converter. In order to achieve small switching losses and consequently high efficiency, LLC have to be design in ZVS region [9, 10]. Design procedure of the LLC converter is based on first harmonic approximation (FHA) and uses the equivalent circuit and functional dependency between quality factor (Q) and normal frequency (Fn) shown on figure 3. In this stipulate condition the load is the contactor's coil and it has constant characteristic after the transient switch on process. This suggests small load regulation and wide region of the line regulation. This condition should guarantee stable work in large input voltage region and robustness form impute disturbance. Figure 4 shows the circuit of the modeled LLC converter. The aim of the modeling and design procedure is to find solution working on resonance. i.e. equality between resonance (Fr) and switching (Fs) frequency shown as point $\mathrm{Fs}=\mathrm{Fr}$ on figure 3 .

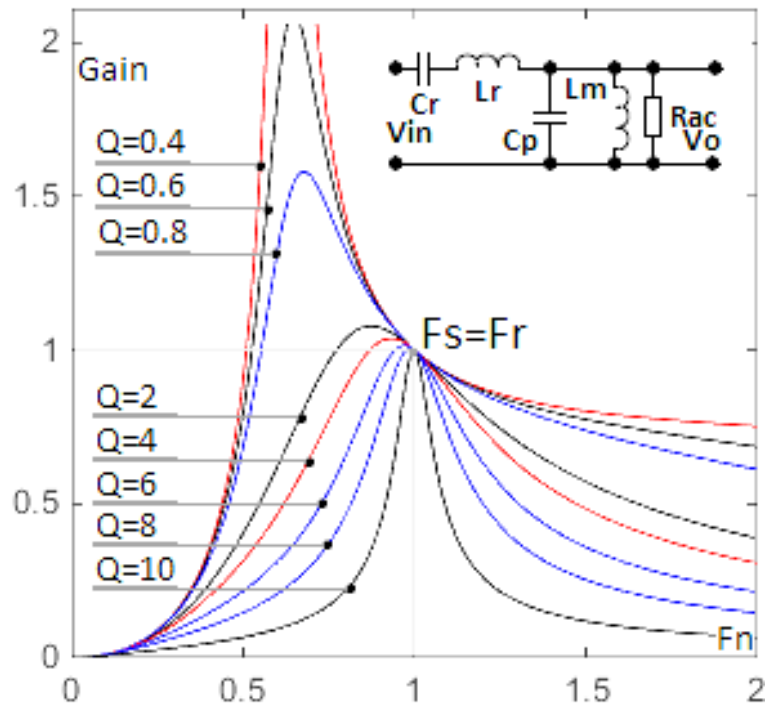

Fig. 3. Functional dependency between gain and normal frequency; substitution circuit of the resonant network.

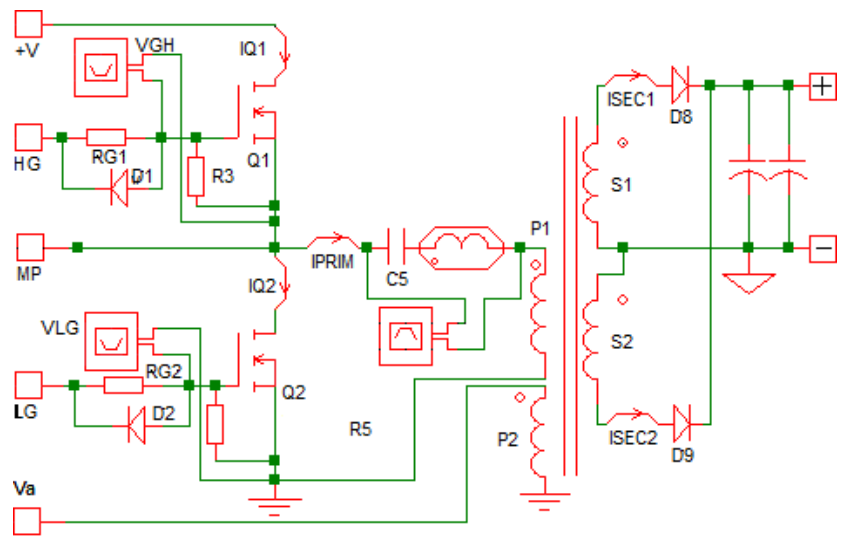

Fig. 4. Schematic of the LLC converter, using for simulation procedure. 


\section{Design considerations}

The complete design procedure for the LLC converter is based on several methodologies $[9,10,11,12]$ and is out of scope of this article. The fundamental mathematical apparatus describes the resonant network (Cr, Lr, Lm fig.2) - for this application it is used in conjunction with the model and simulation presented in the previous section in order to describe the values of the convertor's components:

The voltage gain is:

$$
G\left(Q, m, F_{x}\right)=\left|\frac{V_{o}}{V_{i n}}\right|=\frac{F_{x}^{2}(m-1)}{\sqrt{\left(m \cdot F_{x}^{2}-1\right)^{2}+F_{x}^{2}\left(F_{x}^{2}-1\right)^{2} \cdot(m-1)^{2} \cdot Q^{2}}}
$$

Where:

$$
Q=\frac{\sqrt{L_{r} / C_{r}}}{R_{a c}}
$$

is quality factor;

$$
F_{n}=\frac{F_{s}}{F_{r}}
$$

is normalized frequency. Reflected load resistance is:

$$
R_{a c}=\frac{8}{\pi^{2}} \cdot \frac{N_{p r i}^{2}}{N_{\mathrm{sec}}^{2}} \cdot R_{0}
$$

where $R_{0}$ is output load.

Resonant capacitor $\mathrm{C}_{\mathrm{r}}$ and resonance inductance $\mathrm{L}_{\mathrm{r}}$ are calculated respectively:

$$
C_{r}=\frac{1}{2 \cdot \pi \cdot Q \cdot F_{r} \cdot R_{a c}} ; L_{r}=\frac{1}{\left(2 \cdot \pi \cdot F_{r}\right)^{2} \cdot C_{r}}
$$

The minimum and maximum input voltage described the minimum and maximum gain:

$$
G_{\min }=\frac{n \cdot\left(V_{\text {out } \min }+V_{f}\right)}{V_{\text {irmax }} / 2} ; G_{\max }=\frac{n \cdot\left(V_{\text {out } \max }+V_{f}\right)}{V_{\text {in } \min } / 2}
$$

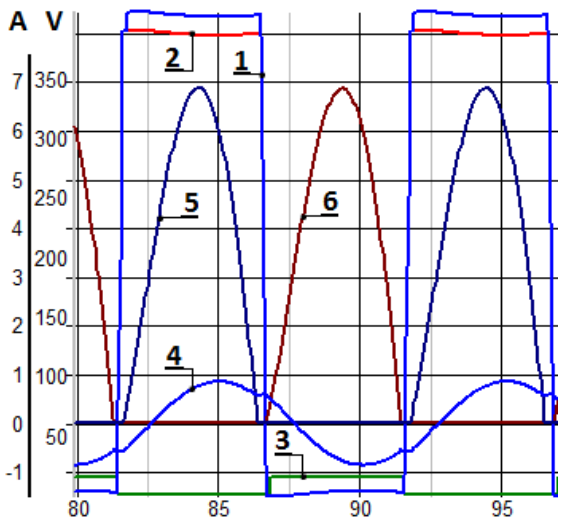

Fig. 5. Simulation results. 1-Q1 gate drive signal; 2-midle point voltage; 3Q2 gate drive signal; 4-first side current; 5,6 - second side current.

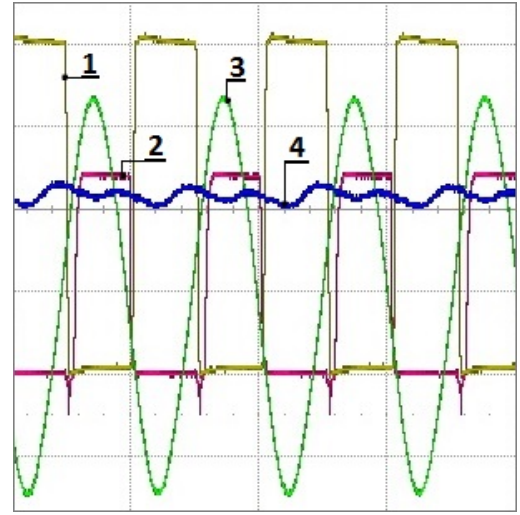

Fig. 6. Experimental results. 1,2-Q1 and Q2 gate drive signals; 3 - first side current; 4 - output DC current

In this design: $\mathrm{Gmin}=0,76$ and $\mathrm{Gmax}=2,1 ; \mathrm{Q}=0,6 ; \mathrm{L}=$ 3,9 . With this parameters input $\mathrm{AC}$ voltages are Vmin. $a c=110 \mathrm{~V} ;$ Vnom. $a c=220 \mathrm{~V} ; \mathrm{Vmax} \cdot \mathrm{ac}=280 \mathrm{~V}$ and in this range the contactor is working normally. After the impute boost converter DC voltages are: Vin.min $=350$; Vin.nom. $d c=400 ;$ Vin. $\max =450$.

Based on this design and the model - simulation results describing the commutation processes of the transistors and their ZVC are presented at figure 5 . This simulation is verified experimentally - measured waveforms for the commutation on the transistors are presented at figure 6.

\section{EXPERIMENTAL RESULTS}

Experimental results of the operation the convertor constructed based on the design considerations described in the previous section - are presented at figures 3,4,5 and 6 .

Figure 3 presents the commutation of the contactor relative to the output of the converter - this waveforms highlights the time required for the contactor to be switched after applying voltage from the invertor, where in this particular case $20-25 \mathrm{~ms}$ were measured. Compared with direct connection, the same contactor turned on for about $80-100 \mathrm{~ms}$. Fast switching is achieved with bigger voltage at the beginning of the process, shown on fig. 4. This function is part of the control system.

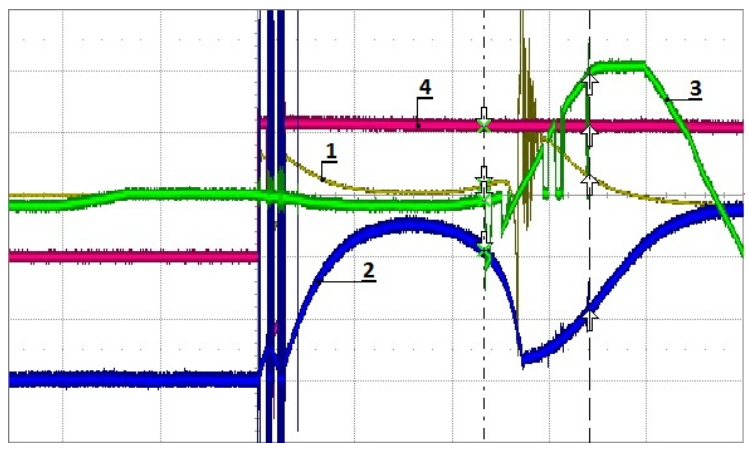

Fig. 7. Turn on process of the electromagnetic contactor with electronic power supply. Flux trough the electromagnetic system (1); current through the contactor's coil (2); current through the contactor's contacts (3); voltage on the coil (4). 


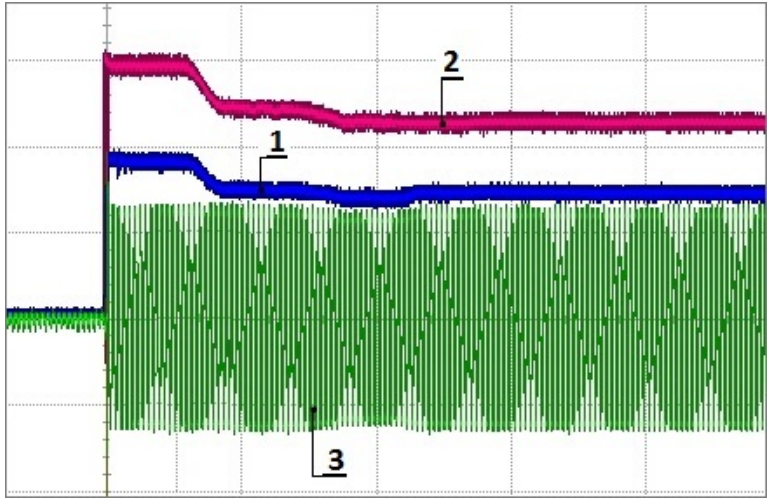

Fig. 8. Turn on process of the electromagnetic contactor (established of the process). Current through the contactor's coil (1); voltage on the coil (2); current through the contactor's contacts (3).

Figure 5 presents the commutation of the contactor in relation to the input voltage of the convertor - this waveform highlights the commutation of the contactor - it can be seen that no overvoltages or overcurrents are present on the coil. Sector A shows vibration of the input switch and sector B vibration of the contactor's contact system.

Figure 6 shows the characteristics of the input Boost converter with PFC function.

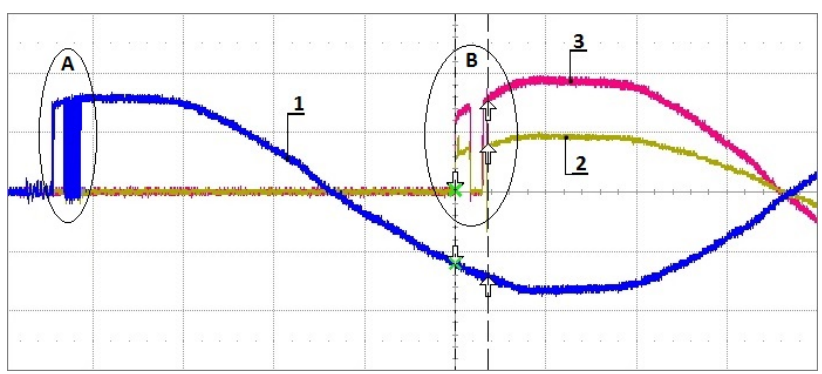

Fig. 9. Voltage on the input of the converter (1); current through the coil (2); voltage on the coil (3)

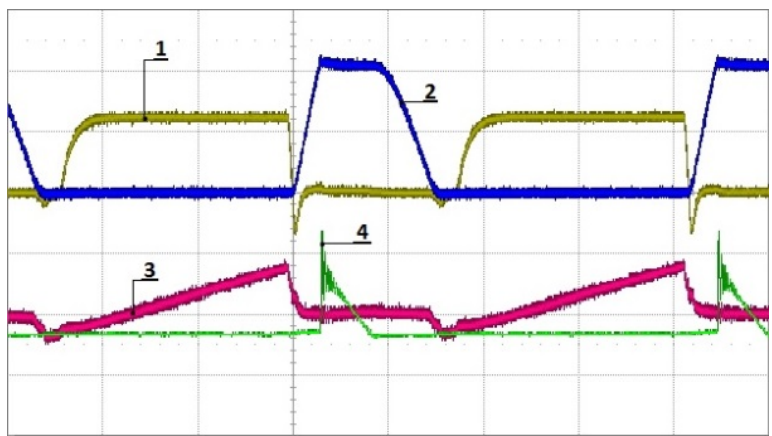

Fig. 10. Gate drive signal (1); Transistor S1 Drain-Source voltage (2); current trough S1 (3); current trough D5 (4)
In addition to the presented waveforms analysis and measurement on the losses (based on [7] and [8]) of the converter were carried. Results show $95 \%$ efficiency of the converter.

\section{CONCLUSIONS}

The suggested circuit based on boost and resonance converter is applicable as power supply system for electromagnetic contactors. The circuit can be design to provide stable work in large region of input voltages which ensure the stable work of the contactor. The time of the turn on process can be decreased with bigger voltage of the beginning of the process as shown fig.4.

Modeling and experimental verification show the functionality of the convertor as a supply for driving contactors, where efficiency for the converter of up to $95 \%$ was achieved. The design of the LLC converter should consider constant load, which is contactor's coil and line regulation in large range. In this case LLC converter is working with zero voltage switching on the first side and zero current switching on the second side. This cause lower switching loses and high efficiency.

\section{REFERENCES}

[1] Chen Li'an, Chen Zhiying, Yu Jigang, et al, "Research on Intelligent AC Contactor with Wide-range Input Voltage," Proceedings of the Third International Symposium on Test Automation and Instrumentation, Vol.2,474-477,Xiamen,China, May,2010.

[2] A. Kelley, J. Cavaroc, J. Ledford, L. Vassalli. "Voltage regulator for contractor ridethrough". IEEE Transactions on Industry Applications, Vol. 36, No. 2, March/April 2000, pp 697-703.

[3] Georgiev A., T. Papanchev, D. Kovachev, „Evaluation of Technical Condition of a Radar with Redundancy“, International Journal of Engineering and Innovative Technology (IJEIT), Vol. 4, Issue 6, Dec. 2014, pp. 185-192, ISSN: 2277-3754

[4] Georgiev A., N. Nikolov, Structural Reliability Analysis of A Star Structured Complex Electronic System, Electronic Journal for Computer Science and Communications, Vol.4, No: 4, pp. 44-51, ISSN: 1314 7846, 2015

[5] Riba, J.-R., A. Garcia, J. Cusidó, Delgado, M, Dynamic model for AC and DC contactors - Simulation and experimental validation, Simulation Modelling Practice and Theory, Volume 19, Issue 9, October 2011 , Pages 1918-1932

[6] Liu R., C. Lee, , Analysis and design of LLC-type series resonan convertor, Electronics Letters, 1988, Volume: 24, Issue: 24, Pages: 1517 - 1519, IET Journals \& Magazine

[7] V. Valchev, A. Marinov, , Improved methodology for power loss measurements in power electronic switches using digital oscilloscope and MATLAB, EPE2010, Ohrid, Macedonia, 6-8 September 2010

[8] A. P. Van den Bossche, D. M. Van de Sype, V. Valchev, Flow calorimeter for equipment test, 31st Annual Conference of IEEE Industrial Electronics Society, 2005. IECON 2005.

[9] Monolithic Power Systems MPS. Application Note for an LLC Resonant Converter Using Resonant Controller HR1000, 2011

[10] Infineon. Design Guide for LLC Converter 2011.

[11] Infineon. Resonant LLC Converter: Operation and Design. 2012

[12] Texas Instruments Incorporated. Designing an LLC Resonant HalfBridge Power Converter 2011 